RESEARCH ARTICLE

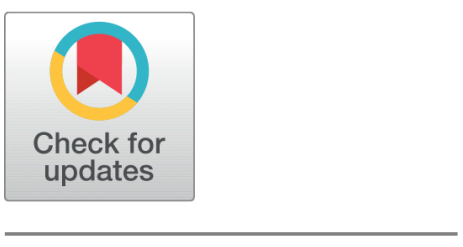

open ACCESS

Received: 28-05-2020

Accepted: 04-06-2020

Published: 17-07-2020

Editor: Dr. Natarajan Gajendran

Citation: Thang TD, Tuyen TM, Truc TN, Phuong PT (2020) Some properties of multivalued positive Boolean dependencies in the database model of block form. Indian Journal of Science and Technology 13(25): 2509-2519. https ://doi.org/10.17485/IJST/v13i25.759

*Corresponding author. Trinh Dinh Thang

Hanoi Pedagogical University No2 thangdhsp2@hpu2.edu.vn

Funding: None

Competing Interests: None

Copyright: (c) 2020 Thang, Tuyen, Truc, Phuong. This is an open access article distributed under the terms of the Creative Commons

Attribution License, which permits unrestricted use, distribution, and reproduction in any medium, provided the original author and source are credited.

Published By Indian Society for Education and Environment (iSee)

\section{Some properties of multivalued positive Boolean dependencies in the database model of block form}

\author{
Trinh Dinh Thang ${ }^{1}$, Tran Minh Tuyen ${ }^{2}$, Trinh Ngoc Truc ${ }^{1}$, Pham Thi Phuong ${ }^{1}$ \\ 1 Hanoi Pedagogical University No2 \\ 2 University Union, Vietnam
}

\section{Abstract}

Objectives: The article proposed a new type of dependency on blocks and slices. Then found and proved the properties of this new dependency. Method: Logical inference methods were used. Findings: A new type of data relationship has been proposed: Multivalued positive Boolean dependencies on block and slice in the database model of block form. From this new concept, the article stated and demonstrated the equivalence of the three types of deduction, namely: $\mathrm{m}$-deduction by logic, $\mathrm{m}$-deduction by block, $\mathrm{m}$-deduction by block has no more than two elements. Next are the necessary and sufficient criteria of the tight m-expression for the set of multivalued positive Boolean dependencies on block and slice, the sufficient properties for a set of functions $\{I, \wedge, \vee\}$. The properties related to this new concept when the block degenerated into relation. Novelty: The proposed new dependency with their properties on the block and on the slice are completely new.

Keywords: Multivalued positive Boolean dependencies; block; Boolean dependencies; block schemes

\section{Introduction}

\subsection{The block, slice of the block}

\section{Definition $1.1^{(1)}$}

Let $\mathrm{R}=\left(\mathrm{id} ; \mathrm{A}_{1}, \mathrm{~A}_{2}, \ldots, \mathrm{A}_{n}\right)$ is a finite set of elements, where id is non-empty finite index set, $\mathrm{A}_{i}(\mathrm{i}=1 . . \mathrm{n})$ is the attribute. Each attribute $\mathrm{A}_{i}(\mathrm{i}=1 . . \mathrm{n})$ there is a corresponding value domain dom $\left(\mathrm{A}_{i}\right)$. A block $\mathrm{r}$ on $\mathrm{R}$, denoted $\mathrm{r}(\mathrm{R})$ consists of a finite number of elements that each element is a family of mappings from the index set id to the value domain of the attributes $\mathrm{A}_{i}(\mathrm{i}=1 . . \mathrm{n})$.

We have:

$$
\mathrm{t} \in \mathrm{r}(\mathrm{R}) \Leftrightarrow \mathrm{t}=\left\{\mathrm{t}^{\mathrm{i}}: \mathrm{id} \rightarrow \operatorname{dom}\left(\mathrm{A}_{\mathrm{i}}\right)\right\}_{\mathrm{i}=1 . \mathrm{n}}
$$

Then, block is denoted $r(R)$ or $r\left(i d ; A_{1}, A_{2}, \ldots, A_{n}\right)$, if without fear of confusion we simply denoted $r$. 


\section{Definition $1.2^{(1)}$}

Let $R=\left(i d ; A_{1}, A_{2}, \ldots, A_{n}\right), r(R)$ is a block over $R$. For each $x \in \operatorname{id}$ we denoted $r\left(R_{x}\right)$ is a block with $R_{x}=\left(\{x\} ; A_{1}, A_{2}, \ldots, A_{n}\right)$ such that:

$$
\mathrm{t}_{\mathrm{x}} \in \mathrm{r}\left(\mathrm{R}_{\mathrm{x}}\right) \Leftrightarrow \mathrm{t}_{\mathrm{x}}=\left\{\mathrm{t}_{\mathrm{x}}^{\mathrm{i}}=\mathrm{t}_{\left.\right|_{x}}^{\mathrm{i}}\right\} \mathrm{i}=1 . . \mathrm{n}, \text { where } \mathrm{t} \in \mathrm{r}(\mathrm{R}), \mathrm{t}=\left\{\mathrm{t}^{\mathrm{i}}: \mathrm{id} \rightarrow \operatorname{dom}\left(\mathrm{A}_{\mathrm{i}}\right)\right\}_{\mathrm{i}=1 . . \mathrm{n}}
$$

Then $\mathrm{r}\left(\mathrm{R}_{x}\right)$ is called a slice of the block $\mathrm{r}(\mathrm{R})$ at point $\mathrm{x}$.

\subsection{Functional dependencies}

Here, for simplicity we use the notation:

$$
\mathbf{x}^{(\mathrm{i})}=\left(\mathrm{x} ; \mathrm{A}_{\mathrm{i}}\right) ; \mathrm{id}^{(\mathrm{i})}=\left\{\mathrm{x}^{(\mathrm{i})} \mid \mathrm{x} \in \mathrm{id}\right\}
$$

and $\mathrm{x}^{(\mathrm{i})}(\mathrm{x} \in \mathrm{id}, \mathrm{i}=1 \ldots \mathrm{n})$ is called an index attribute of block scheme $\mathrm{R}=\left(\mathrm{id} ; \mathrm{A}_{1}, \mathrm{~A}_{2}, \ldots, \mathrm{A}_{n}\right)$.

Definition $1.3^{(2)}$

Let $R=\left(\right.$ id; $\left.A_{1}, A_{2}, \ldots, A_{n}\right), r(R)$ is a block over $R$ and $\mathrm{X}, \mathrm{Y} \subseteq \bigcup_{\mathrm{i}=1}^{\mathrm{n}} \mathrm{id}^{(\mathrm{i})}, \mathrm{X} \rightarrow \mathrm{Y}$ is a notation of functional dependency. A block $r$ satisfies $X \rightarrow$ Y if:

\section{Definition $1.4^{(2)}$}

$$
\forall \mathrm{t}_{1}, \mathrm{t}_{2} \in \mathrm{R} \text { such that } \mathrm{t}_{1}(\mathrm{X})=\mathrm{t}_{2}(\mathrm{X}) \text { then } \mathrm{t}_{1}(\mathrm{Y})=\mathrm{t}_{2}(\mathrm{Y})
$$

Let block scheme $\alpha=(\mathrm{R}, \mathrm{F}), \quad \mathrm{R}=\left(\mathrm{id} ; \mathrm{A}_{1}, \mathrm{~A}_{2}, \ldots, \mathrm{A}_{\mathrm{n}}\right) \mathrm{F}$ is the set of functional dependencies over $\mathrm{R}$. Then, the closure of $\mathrm{F}$ denoted $\mathrm{F}^{+}$is defined as follows:

$$
\mathrm{F}^{+}=\{\mathrm{X} \rightarrow \mathrm{Y} \mid \mathrm{F} \Rightarrow \mathrm{X} \rightarrow \mathrm{Y}\}
$$

If $\mathrm{X}=\left\{\mathrm{x}^{(\mathrm{m})}\right\} \subseteq \mathrm{id}^{(\mathrm{m})}, \mathrm{Y}=\left\{\mathrm{y}^{(\mathrm{k})}\right\} \subseteq \mathrm{id}^{(\mathrm{k})}$ then we denoted functional dependency $X \rightarrow \mathrm{Y}$ is simply $x^{(m)} \rightarrow y^{(k)}$.

The block $r$ satisfies $\mathbf{x}^{(m)} \rightarrow \mathbf{y}^{(\mathbf{k})}$ if $\forall \mathbf{t}_{1}, \mathbf{t}_{2} \in \mathbf{r}$ such that $\mathbf{t}_{1}\left(\mathbf{x}^{(m)}\right)=\mathbf{t}_{2}\left(\mathbf{x}^{(m)}\right)$ then $t_{1}\left(\mathbf{y}^{(k)}\right)=t_{2}\left(\mathbf{y}^{(k)}\right)$,

where: $\mathrm{t}_{1}\left(\mathrm{x}^{(\mathrm{m})}\right)=\mathrm{t}_{1}\left(\mathrm{x} ; \mathrm{A}_{\mathrm{m}}\right), \mathrm{t}_{2}\left(\mathrm{x}^{(\mathrm{m})}\right)=\mathrm{t}_{2}\left(\mathrm{x} ; \mathrm{A}_{\mathrm{m}}\right), \quad \mathrm{t}_{1}\left(\mathrm{y}^{(\mathrm{k})}\right)=\mathrm{t}_{1}\left(\mathrm{y} ; \mathrm{A}_{\mathrm{k}}\right), \quad \mathrm{t}_{2}\left(\mathrm{y}^{(\mathrm{k})}\right)=\mathrm{t}_{2}\left(\mathrm{y} ; \mathrm{A}_{\mathrm{k}}\right)$.

Let block scheme $\mathrm{R}=\left(\mathrm{id} ; \mathrm{A}_{1}, \mathrm{~A}_{2}, \ldots, \mathrm{A}_{n}\right)$, we denoted the subsets of functional dependencies over $\mathrm{R}$ :

$$
\begin{gathered}
\mathrm{F}_{\mathrm{h}}=\left\{\mathrm{X} \rightarrow \mathrm{Y} \mid X=\bigcup_{i \in A} x^{(i)}, Y=\bigcup_{j \in B} x^{(j)} \mathrm{A}, \mathrm{B} \subseteq\{1,2, \ldots, \mathrm{n}\}, \mathrm{x} \in \mathrm{id}\right\} \\
\mathrm{F}_{\mathrm{hx}}=\mathrm{F}_{\left.h\right|_{\bigcup_{i=1}^{n} x^{(i)}}}=\left\{X \rightarrow Y \in F_{h} \mid X, Y \subseteq \bigcup_{i=1}^{n} x^{(i)}\right\}
\end{gathered}
$$

\section{Definition $1.5^{(3)}$}

Let block scheme $\alpha=\left(\mathrm{R}, \mathrm{F}_{\mathrm{h}}\right), \quad \mathrm{R}=\left(\mathrm{id} ; \mathrm{A}_{1}, \mathrm{~A}_{2}, \ldots, \mathrm{A}_{\mathrm{n}}\right)$, then $F_{h}$ is called the complete set of functional dependencies if:

$$
F_{h x}=F_{\left.h\right|_{i=1} ^{n} x^{(i)}} \quad \text { is the same with every } x \in i d
$$

A more specific way:

$\mathrm{F}_{h x}$ is the same with every $\mathrm{x} \in \mathrm{id}$ mean $\forall \mathrm{x}, \mathrm{y} \in \mathrm{id}: \mathrm{M} \rightarrow \mathrm{N} \in \mathrm{F}_{\mathrm{hx}} \Leftrightarrow \mathrm{M}^{\prime} \rightarrow \mathrm{N}^{\prime} \in \mathrm{F}_{\text {hy }}$ with $\mathrm{M}^{\prime}, \mathrm{N}^{\prime}$ respectively, formed from $\mathrm{M}, \mathrm{N}$ by replacing $\mathrm{x}$ by $\mathrm{y}$.

\subsection{Closure of the index attributes sets:}

\section{Definition $1.6^{(3)}$}

Let block scheme $\alpha=(\mathrm{R}, \mathrm{F}), \mathrm{R}=\left(\mathrm{id} ; \mathrm{A}_{1}, \mathrm{~A}_{2}, \ldots, \mathrm{A}_{\mathrm{n}}\right), \mathrm{F}$ is the set of functional dependencies on $R$.

With each $\mathrm{X} \subseteq \bigcup_{i=1}^{n} \mathrm{id}^{(i)}$, we define closure of $\mathrm{X}$ for $\mathrm{F}$ denoted $\mathrm{X}^{+}$as follows:

$$
\mathrm{X}^{+}=\left\{\mathrm{x}^{(i)} \mid \mathrm{X} \rightarrow \mathrm{x}^{(\mathrm{i})} \in \mathrm{F}^{+}, \mathrm{x} \in \mathrm{id}, \mathrm{i}=1 . . \mathrm{n}\right\}
$$

We denote the set of all subsets of a set $\bigcup_{i=1}^{n} \mathrm{id}^{(i)}$ as set SubSet $\left(\bigcup_{i=1}^{n} \mathrm{id}^{(i)}\right)$. 


\subsection{Key of the block scheme $\alpha=(\mathbf{R}, \mathbf{F})$}

\section{Definition $1.7^{(4)}$}

Let block scheme $\alpha=(R, F), R=\left(i d ; A_{1}, A_{2}, \ldots, A_{n}\right)$, Fis the set of functional dependencies on $R, K \subseteq \bigcup_{i=1}^{n} \mathrm{id}^{(\mathrm{i})} . K$ called a key of block schema $\alpha$ if it satisfies two conditions:

i) $\mathrm{K} \rightarrow \mathrm{x}^{(\mathrm{i})} \in \mathrm{F}^{+}, \forall \mathrm{x} \in \mathrm{id}, \mathrm{i}=1$..n.

ii) $\forall \mathrm{K}^{\prime} \subset \mathrm{K}$ then $\mathrm{K}^{\prime}$ has no properties $i$ ).

If $\mathrm{K}$ is a key and $\mathrm{K} \subseteq \mathrm{K}^{\prime \prime}$ then $\mathrm{K}$ " called a super key of the block scheme $\mathrm{R}$ for $\mathrm{F}$.

\section{Multivalued Boolean formulas}

\subsection{Multivalued boolean formulas}

\section{Definition 2.1 ${ }^{(5)}$}

For the set of Boolean values $\mathrm{B}=\left\{b_{1}, b_{2}, \ldots, b_{k}\right\}$ including $k$ values in $[0 ; 1], k \geq 2$ are in ascending order and satisfy the following conditions:

(i) $0 \in B$.

(ii) $\forall b \in B \quad \Rightarrow 1-b \in B$.

We choose the operations and basic multivalued logical function: $\forall a, b \in B$

- $a \wedge b=\min (a, b)$,

- $a \vee b=\max (a, b)$,

- $\neg a=1-a$

- With each value $b \in B$, we define the function $\mathrm{I}_{b}$ :

$$
\forall \mathrm{x} \in \mathrm{B}: \quad \mathrm{I}_{\mathrm{b}}(\mathrm{x})=1 \text { if } \mathrm{x}=\mathrm{b} \text { and } \mathrm{I}_{\mathrm{b}}(\mathrm{x})=0 \text { if } \mathrm{x} \neq \mathrm{b}
$$

The functions $\mathrm{I}_{b}, b \in B$ called generalized negative functions.

\section{Definition 2.2 ${ }^{(5)}$}

Let $\mathrm{P}=\left\{\mathrm{x}_{1}, \mathrm{x}_{2}, \ldots, \mathrm{x}_{n}\right\}$ is a finite set of Boolean variables, $B$ is the set of Boolean values. Then the multivalued boolean formulas $(\mathrm{CTBĐT)} \mathrm{also} \mathrm{known} \mathrm{as} \mathrm{multivalued} \mathrm{logic} \mathrm{formulas} \mathrm{are} \mathrm{constructed} \mathrm{as} \mathrm{follows:}$

1. Each value in $B$ is a CTBĐT.

2. Each variable in $\mathrm{P}$ is a $\mathrm{CTBÐT.}$

3. Each function $\mathrm{I}_{b}, b \in B$ is a CTBĐT.

4. If $\mathrm{a}$ is a multivalued Boolean formula then (a) is a CТВÐТ.

5. If $\mathrm{a}$ and $\mathrm{b}$ are СТВÐТ then $a \wedge b, a \vee b$ and $\neg a$ is a СТВÐТ.

6. Only formulas created by rules from (1) -(5) are СТВĐT.

We denote $\operatorname{MVL}(\mathrm{P})$ as a set of CTBĐT building on the set of variables $\mathrm{P}=\left\{\mathrm{x}_{1}, \mathrm{x}_{2}, \ldots, \mathrm{x}_{n}\right\}$ and set of values $\mathrm{B}=\left\{\mathrm{b}_{1}, \mathrm{~b}_{2}, \ldots, \mathrm{b}_{k}\right\}$ including $\mathrm{k}$ values in $[0 ; 1], k \geq 2$.

Definition $2.3^{(5)}$

We define $a \rightarrow b$ equivalent to $C T B Đ T(\neg a) \vee b$ and then: $a \rightarrow b=\max (1-a, b)$.

\section{Definition 2.4 ${ }^{(5)}$}

Each vector of elements $v=\left\{v_{1}, v_{2}, \ldots, v_{n}\right\}$ in space $B^{n}=B X B X \ldots X$ B is called a value assignment. Thus, with each CTBĐT $f \in M V L(P)$ we have $f(v)=f\left(v_{1}, v_{2}, \ldots, v_{n}\right)$ is the value of formula ffor $v$ value assignments.

In the case where there is no confusion, we understand the symbol $\mathrm{X} \subseteq \mathrm{P}$ at the same time performing for the following subjects:

- An attribute set in P.

- A set of logical variables in $P$. 
- A multivalued Boolean formula is the logical union of variables in X.

On the other hand, if $\mathrm{X}=\left\{\mathrm{B}_{1}, \mathrm{~B}_{2}, \ldots, \mathrm{B}_{n}\right\} \subseteq \mathrm{P}$, we denoted:

$\wedge X=B_{1} \wedge B_{2} \wedge \ldots \wedge B_{n}$ called the associational form.

$\vee X=\mathrm{B}_{1} \vee \mathrm{B}_{2} \vee \cdots \vee \mathrm{B}_{\mathrm{n}}$ called the recruitmental form.

We call formula $\mathrm{f}: \mathrm{Z} \rightarrow \mathrm{V}$ is :

- Multivalued derivative formula if $\mathrm{Z}$ and $\mathrm{V}$ has the associational form, mean:

$$
\mathrm{f}: \wedge Z \rightarrow \wedge \mathrm{V}
$$

- Strong multivalued derivative formula if $\mathrm{Z}$ has the ecruitmental form and $\mathrm{V}$ has the associational form, mean:

$$
f: \vee Z \rightarrow \wedge V
$$

- Weak multivalued derivative formula if $\mathrm{Z}$ has the associational form and $\mathrm{V}$ has the ecruitmental form, mean:

$$
\mathrm{f}: \wedge \mathrm{Z} \rightarrow \vee V
$$

- Duality multivalued derivative formula if $\mathrm{Z}$ and $\mathrm{V}$ are in recruitment form, mean:

$$
f: \vee Z \rightarrow \vee V
$$

For each finite set CTBĐT $F=\left\{f_{1}, f_{2}, \ldots, f_{m}\right\}$ in $\operatorname{MVL}(P)$, we consider $F$ as a formatted formula $F=f_{1} \wedge f_{2} \wedge \ldots \wedge f_{m}$. Then we have:

$$
\mathrm{F}(\mathrm{v})=\mathrm{f}_{1}(\mathrm{v}) \wedge \mathrm{f}_{2}(\mathrm{v}) \wedge \ldots \wedge \mathrm{f}_{\mathrm{m}}(\mathrm{v})
$$

\subsection{Table of values and truth tables}

With each formula $\mathrm{f}$ on $\mathrm{P}$, table of values for $\mathrm{f}$, denote that $\mathrm{V}_{f}$ contains $\mathrm{n}+1$ columns, with the first $\mathrm{n}$ columns containing the values of the variables in $\mathrm{U}$, and the last column contains the value of $\mathrm{f}$ for each values signment of the corresponding row. Thus, the value table contains $\mathrm{k}^{\mathrm{n}}$ row, $\mathrm{n}$ is the element number of $\mathrm{P}, \mathrm{k}$ is the element number of $B$.

\section{Definition $2.5^{(5)}$}

Let $m \in[0 ; 1]$, truth table with $m$ threshold off or the $m$-truth table off, denoted $T_{f, m}$ is the set of assignments $v$ such that $f(v)$ receive value not less than $m$ :

$$
\mathrm{T}_{f, m}=\left\{\mathrm{v} \in B^{\mathrm{n}} \mid \mathrm{f}(\mathrm{v}) \geq \mathrm{m}\right\}
$$

Then, the m-truth table $T_{F, m}$ of finite sets of formulas $F$ on $P$, is the intersection of the $m$-truth tables of each member formula in $F$.

$$
T_{F, m}=\bigcap_{f \in F} T_{f, m}
$$

We have: $v \in T_{F, m}$ necessary and sufficient are $\forall f \in F: f(v) \geq m$.

\subsection{Logical deduction}

\section{Definition 2.6 ${ }^{(5)}$}

Let $f$, $g$ is two CТВÐТ and value $m \in B$. We say formula f derives formula grom threshold $m$ and denoted $f \mid={ }_{m} g$ if $T_{f, m} \subseteq$ $T_{g, m}$. We say $f$ and $g$ are two m-equivalent formulas, denoted $f \equiv_{x}$ g if $T_{f, m}=T_{g, m}$.

With $F$, $G$ in $M V L(P)$ and value $m \in[0 ; 1]$, we have F derives $G$ from threshold $m$, denoted $F \mid={ }_{m} G$ if $T_{F, m} \subseteq T_{G, m}$. Moreover, we say $F$ and $G$ are $m$-equivalents, denoted $F \equiv_{n}$ G if $T_{F, m}=T_{G, m}$.

\subsection{Multivalued positive Boolean formula}

Definition $2.7^{(5)}$

Formula $f \in M V L(P)$ is called a multivalued positive Boolean formula (CTBDĐT) if $f(e)=1$ with e is the unit value assignment: $e=(1,1, \ldots, 1)$, we denoted $\operatorname{MVP}(P)$ is the set of all multivalued positive Boolean formulas on $P$. 


\section{Research results}

\subsection{The m-truth block of the data block}

\section{Definition 3.1}

Let $R=\left(i d ; A_{1}, A_{2}, \ldots, A_{n}\right), r(R)$ is a block on $R, U=\bigcup_{i=1}^{n} i d^{(i)},|i d|=s$, We call each vector of elements $v=\left\{v_{i 1}, v_{i 2}, \ldots, v_{i n}\right\}$ $i=1 . . s$ in space $B^{n x s}$ is a value assignment. Thus, with each $C T B Đ T f \in M V L(U)$ we have $f(v)=f\left(v_{i 1}, v_{i 2}, \ldots, v_{i n}\right){ }_{i=1 . . s}$ is the value of formula f for $v$ value assignments.

Example 3.1: Let $\mathrm{R}=\left(\{1,2\}, \mathrm{A}_{1}, \mathrm{~A}_{2}, \mathrm{~A}_{3}\right)$ then $\mathrm{U}=\left\{1^{(1)}, 1^{(2)}, 1^{(3)}, 2^{(1)}, 2^{(2)}, 2^{(3)}\right\}, B=\{0,0.5,1\}$.

Let $\mathrm{v}=\left(\begin{array}{ccc}0.5 & 1 & 0.5 \\ 1 & 0.5 & 0.5\end{array}\right), \mathrm{f}=1^{(1)} 1^{(2)} 2^{(1)} 2^{(2)} \rightarrow 1^{(3)} 2^{(3)}$, then we have $\mathrm{f}(\mathrm{v})=\max (1-\min (0.5,1,1,0.5), \min (0.5,0.5))$. Inferred: $\mathrm{f}(\mathrm{v})=0.5$.

We have two special assignment:

Unit assignment: $e=\left(\begin{array}{ccc}1 & 1 & 1 \\ \cdot & \cdot & \cdot \\ 1 & 1 & 1\end{array}\right)$ and the assignment value $0: Z=\left(\begin{array}{ccc}0 & 0 & 0 \\ \cdot & \cdot & \cdot \\ 0 & 0 & 0\end{array}\right)$

\section{Definition 3.2}

Let $m \in[0 ; 1]$, truth block threshold $m$ of f or $m$-truth block off, denoted $T_{f, m}$ is the set of assignments $v$ such that $f(v)$ receive value not less than $m$ :

$$
T_{f, m}=\left\{v \in B^{\mathrm{nxs}} \mid f(v) \geq m\right\}
$$

Then, the m-truth block $T_{F, m}$ of a finite set of formulas $F$ on $U$, is the intersection of the $m$-truth blocks of each formula of member fin $F$.

$$
T_{F, m}=\bigcap_{f \in F} T_{f, m}
$$

We have: $v \in T_{F, m}$ if and only if $\forall f \in F: f(v) \geq m$.

With $|B|=\mathrm{k}$ then $\left|B^{\text {nxs }}\right|=\mathrm{k}^{\text {nxs }}$, we have the following theorem:

\section{Theorem 3.1}

Let block $\mathrm{T}=\left\{\mathrm{t}_{1}, \mathrm{t}_{2}, \ldots, \mathrm{t}_{\mathrm{d}}\right\} \subseteq B^{\mathrm{nxs}}$ and values $m_{1}, m_{2}, \ldots, m_{d}$ trong $B, I \leq d \leq k^{n \times s}$. Then:

a) There exists one CTBĐT $f$ satisfies the following two properties:

(i) $\forall t_{i} \in T: f\left(t_{i}\right)=m_{i}$,

(ii) $\forall t \in \mathrm{B}^{\text {nxs }} \mid T: f(t)=0$

b) With every slice: $\mathrm{T}_{\mathrm{x}}, \mathrm{x} \in \mathrm{id},|\mathrm{id}|=\mathrm{s}, \quad \mathrm{CTBĐT} f_{\mathrm{x}}=\mathrm{f}_{\left.\right|_{\mathrm{T}_{\mathrm{x}}}}$ also satisfies the following two properties:

(iii) $\forall t_{x i} \in T_{x}: f_{x}\left(t_{x i}\right)=m_{i}, T_{x}$

(iv) $\forall \mathrm{t}_{\mathrm{x}} \in B^{\mathrm{n}} \mid \mathrm{T}_{\mathrm{x}}: \mathrm{f}_{\mathrm{x}}\left(\mathrm{t}_{\mathrm{x}}\right)=0$

Proof:

a) With each $\mathrm{t}_{\mathrm{i}} \in \mathrm{T}: \mathrm{t}_{\mathrm{i}}=\left\{\mathrm{t}_{\mathrm{ij} 1}, \mathrm{t}_{\mathrm{ij} 2}, \ldots, \mathrm{t}_{\mathrm{ijn}}\right\}_{\mathrm{j}=1 . . \mathrm{s}}, 1 \leq \mathrm{i} \leq \mathrm{d}$, we built formula:

$$
h_{i}\left(x^{(j 1)}, x^{(j 2)}, \ldots, x^{(i n)}\right)_{j=1 . . s}=\wedge\left(I_{t i j 1}\left(x^{(j 1)}\right), I_{t j 2}\left(x^{(j 2)}\right), \ldots, I_{t j i n}\left(x^{(i n)}\right), m_{i}\right)_{j=1 . . S}
$$

and we have: if $\left(\mathrm{x}^{(j 1)}, \mathrm{x}^{(j 2)}, \ldots, \mathrm{x}^{(\mathrm{jn})}\right)_{\mathrm{j}=1 . . \mathrm{s}}=\mathrm{t}_{\mathrm{i}}=\left\{\mathrm{t}_{i j 1}, \mathrm{t}_{\mathrm{ij} 2}, \ldots, \mathrm{t}_{\mathrm{ijn}}\right\}_{j=1 . . s}$ then:

$$
\mathrm{h}_{\mathrm{i}}\left(\mathrm{t}_{\mathrm{i}}\right)=\mathrm{m}_{\mathrm{i}}, \mathrm{h}_{\mathrm{i}}(\mathrm{t})=0 \text { with } \mathrm{t} \neq \mathrm{t}_{\mathrm{i}}, 1 \leq \mathrm{i} \leq \mathrm{d}
$$

Therefore, if we set:

$$
\mathrm{f}\left(\mathrm{x}^{(j 1)}, \mathrm{x}^{(j 2)}, \ldots, \mathrm{x}^{(\mathrm{jn})}\right)_{\mathrm{j}=1 . . \mathrm{s}}=\left(\mathrm{h}_{1} \vee \mathrm{h}_{2} \vee \cdots \vee \mathrm{h}_{\mathrm{d}}\right)\left(\mathrm{x}^{(\mathrm{j} 1)}, \mathrm{x}^{(j 2)}, \ldots, \mathrm{x}^{(\mathrm{jn})}\right)_{\mathrm{j}=1 . . \mathrm{s}}
$$


then $\mathrm{f}$ is the formula to look for.

Indeed, we have:

$$
\mathrm{f}\left(\mathrm{t}_{\mathrm{i}}\right)=\left(\mathrm{h}_{1} \vee \mathrm{h}_{2} \vee \cdots \vee \mathrm{h}_{\mathrm{d}}\right)\left(\mathrm{t}_{\mathrm{i}}\right)=\mathrm{h}_{1}\left(\mathrm{t}_{\mathrm{i}}\right) \vee \mathrm{h}_{2}\left(\mathrm{t}_{\mathrm{i}}\right) \vee \cdots \vee \mathrm{h}_{\mathrm{i}}\left(\mathrm{t}_{\mathrm{i}}\right) \vee \cdots \vee \mathrm{h}_{\mathrm{d}}\left(\mathrm{t}_{\mathrm{i}}\right)
$$

.Which according to the properties of

$$
\begin{aligned}
& h_{i:} \quad h_{i}\left(t_{i}\right)=h_{i}\left(\left\{t_{i j 1}, t_{i j 2}, \ldots, t_{i j n}\right\}_{j=1 . . s}\right)=\wedge\left(I_{t i j 1}\left(t_{i j 1}\right), I_{t i j 2}\left(t_{i j 2}\right), \ldots, I_{t j n}\left(t_{i j n}\right), m_{i}\right)_{j=1 . . s}=m_{i} \\
& h_{i}(t)=0 \text { vi } t \neq t_{i}, 1 \leq \mathrm{i} \leq d
\end{aligned}
$$

So infer: $f\left(t_{i}\right)=m_{i}, 1 \leq i \leq d$ and $\forall t \in B^{\text {nxs }} \backslash T: f(t)=0 \Rightarrow f$ is CTBĐT to look for.

b) From CTBĐT f we have: $f_{x}=\left(h_{x 1} \vee h_{x 2} \vee \ldots v h_{x d}\right)$ Then:

$\forall \mathrm{t}_{\mathrm{xi}} \in \mathrm{T}_{\mathrm{x}}: \mathrm{f}_{\mathrm{x}}\left(\mathrm{t}_{\mathrm{xi}}\right)=\left(\mathrm{h}_{\mathrm{x} 1} \vee \mathrm{h}_{\mathrm{x} 2} \vee \ldots \mathrm{v}_{\mathrm{hxd}}\right)\left(\mathrm{t}_{\mathrm{xi}}\right)=\mathrm{h}_{\mathrm{x} 1}\left(\mathrm{t}_{\mathrm{xi}}\right) \vee \mathrm{h}_{\mathrm{x} 2}\left(\mathrm{t}_{\mathrm{xi}}\right) \vee \ldots \mathrm{vh}_{\mathrm{xi}}(\mathrm{txi}) \vee \ldots \mathrm{vh}_{\mathrm{xd}}$

Which we have: $h_{x i}\left(t_{x i}\right)=h_{x i}\left(\left\{t_{x i 1}, t_{x i 2} \ldots \ldots, x t_{x i n}\right\}\right)=\wedge\left(I_{x x i 1}\left(t_{t x i 1}\right), I_{\text {txi2 }}\left(t_{x i 2}\right), \ldots, I_{\text {txin }}\left(t_{x i n}\right), m_{i}\right)=m_{i}$

$\mathrm{h}_{\mathrm{xi}}\left(\mathrm{t}_{\mathrm{x}}\right)=0$ với $\mathrm{t}_{\mathrm{x}} \neq \mathrm{t}_{\mathrm{xi}}, 1 \leq \mathrm{i} \leq \mathrm{d}$.

we infer: $f_{x}\left(t_{x i}\right)=m_{i}, 1 \leq i \leq d$

and $\forall \mathrm{t}_{\mathrm{x}} \in B^{\mathrm{n}} \backslash \mathrm{T}: \mathrm{f}_{\mathrm{x}}\left(\mathrm{t}_{\mathrm{x}}\right)=0 \Rightarrow \mathrm{f}_{\mathrm{x}}$ satisfies 2 conditions required.

Consequence 3.1: With each block $T \subseteq B^{n x s}, T \neq \varnothing$ and each value $m>0$ in $B$, exists one CTBĐT $f$ take $T$ as the $m$-truth block, and $f_{x}$ get $T_{x}$ as the $m$-truth block.

Proof:

Use the result of the theorem 3.1 with special cases: $\mathrm{m}_{1}=\mathrm{m}_{2}=\ldots=\mathrm{m}_{d}=\mathrm{m}$ we obtained CTBĐT $\mathrm{f}$ satisfies two conditions:

(i) $\forall t_{i} \in T: f\left(t_{i}\right)=m$

(ii) $\forall t \in \mathrm{B}^{\text {nxs }} \mid T: f(t)=0$

and then CTBĐT $\mathrm{f}_{x}$ also satisfies two conditions:

(iii) $\forall t_{x i} \in T_{x}: f\left(t_{x i}\right)=m$

(iv) $\forall t_{x i} \in \mathrm{B}^{\mathrm{n}} \mid T_{x}: f\left(t_{x i}\right)=0$. Thence inferred: $\mathrm{T}_{f, m}=\mathrm{T}$ và $\mathrm{T}_{f x, m}=\mathrm{T}_{x}$.

\section{Definition 3.3}

Let $R=\left(i d ; A_{1}, A_{2}, \ldots, A_{n}\right), r(R)$ is a block on $R, U=\bigcup_{i=1}^{n} i d^{(i)}$, each CTBĐT $f \in M V L(U)$ is called a multivalued positive Boolean formula (CTBDĐT) if $f(e)=1$, with i e is the unit value assignment. Here: $e=\left(\begin{array}{ccc}1 & 1 & 1 \\ . & . & . \\ 1 & 1 & 1\end{array}\right)$

\section{Example 3.2:}

Let $\mathrm{R}=\left(\{1,2\}, \mathrm{A}_{1}, \mathrm{~A}_{2}, \mathrm{~A}_{3}\right), \mathrm{U}=\left\{1^{(1)}, 1^{(2)}, 1^{(3)}, 2^{(1)}, 2^{(2)}, 2^{(3)}\right\} B=\{0,0.5,1\}$. Then:

- The formulars: $1^{(1)} \wedge 1^{(2)} \wedge 2^{(1)} \wedge 2^{(2)}, \quad 1^{(1)} \wedge 1^{(2)} \wedge 2^{(1)} \rightarrow 2^{(2)}$ are the CTBDĐT.

- The formulars: $1^{(2)} \wedge\left(\neg 2^{(3)}\right), \quad\left(\neg 1^{(3)}\right) \wedge\left(\neg 2^{(1)}\right)$ are not the CTBDĐT.

We denoted MVP(U) is the set of all multivalued positive Boolean formulas on $U$.

\section{Definition 3.4}

Let $R=\left(i d ; A_{1}, A_{2}, \ldots, A_{n}\right), r(R)$ is a block on $R$, we denote $d_{i}$ is the value domain of the attribute $A_{i}$ (is also of index attribute $\left.x^{(i)}, x \in i d\right), 1 \leq i \leq n$. Then, for each value domain we consider mapping: $\alpha_{i}: d_{i} x d_{i} \rightarrow B$ satisfies the following conditions:

(i) Reflectivity: $\forall a \in d_{i}: \alpha_{i}(a, a)=1$,

(ii) Symmetry: $\forall a, b \in d_{i}: \alpha_{i}(a, b)=\alpha_{i}(b, a)$,

(iii) Sufficiency: $\forall m \in B, \exists a, b \in d_{i}: \alpha_{i}(a, b)=m$.

Thus, we see the mapping $\alpha_{i}$ are the relationships above $\mathrm{d}_{i}$ satisfies the reflective, symmetrical and sufficiency properties. Equality relationships with logic of two values $B=\{0,1\}$ is the separate case of the above relationship.

\section{Definition 3.5}


Let $R=\left(i d ; A_{1}, A_{2}, \ldots, A_{n}\right), r(R)$ is a block on $R, u, v \in r$, mappings $\alpha_{i}$ define on each value domain $d_{i}, \quad 1 \leq i \leq n$. we call $\alpha(u, v)$ is the value assignment:

$$
\alpha(u, v)=\left(\alpha_{1}\left(u \cdot x^{(1)}, v \cdot x^{(1)}\right), \alpha_{2}\left(u \cdot x^{(2)}, v \cdot x^{(2)}\right), \ldots, \alpha_{n}\left(u \cdot x^{(n)}, v \cdot x^{(n)}\right)\right)_{x \in i d}
$$

Then, for each block $r$, we denote the truth block of block $r$ as $T_{r}$ :

$$
T_{r}=\{\alpha(u, v) \mid u, v \in r\}
$$

If block $\mathrm{r}$ contains at least a certain element $\mathrm{k}$ then: $\alpha(\mathrm{u}, \mathrm{u})=1 \Rightarrow \mathrm{e} \in \mathrm{T}_{\mathrm{r}}$.

In the case $\mathrm{id}=\{\mathrm{x}\}$, then the block degenerates into a relation and the concept of the truth block of the block becomes the concept of truth table of relation in the relational data model. In other words, the truth block of a block is to expand the concept of the truth table of relation in the relational data model.

\subsection{The multivalued positive Boolean dependencies on block}

\section{Definition 3.6}

Let $R=\left(i d ; A_{1}, A_{2}, \ldots, A_{n}\right), r(R)$ is a block on $R, U=\bigcup_{i=1}^{n}$ i d ${ }^{(i)}$, we call each multivalued positive Boolean formula in $M V P(U)$ is a multivalued positive Boolean dependency (PTBDÐT) on block.

We say block $r$ is $m$-satisfying the multivalued positive Boolean dependency fand denoted $r(f, m)$ if $T_{r} \subseteq T_{f, m}$.

The block $r$ is $m$-satisfying set of multivalued positive Boolean dependency $F$ and denoted $r(F, m)$ if $r$ satisfies all PTBDĐT $f$ in F:

$$
r(F, m) \Leftrightarrow \forall f \in F: r(f, m) \Leftrightarrow T_{r} \subseteq T_{F, m}
$$

If $r(f, m)$ then we say PTBDĐT $f$ is m-right in the block $r$.

\section{Proposition 3.1}

Let $R=\left(i d ; A_{1}, A_{2}, \ldots, A_{n}\right), r(R)$ is a block on $R, U=\bigcup_{i=1}^{n} i d^{(i)}$. Then:

i) If $r$ is $m$-satisfying the multivalued positive Boolean dependency $f: r(f, m)$ then $r_{x}\left(f_{x}, m\right), \quad \forall x \in i d$

ii) If $r$ is $m$-satisfying set of multivalued positive Boolean dependency $F: r(F, m)$ then $r_{x}\left(F_{x}, m\right), \forall x \in$ id

Proof

i) Under the assumption we have $\mathrm{r}(\mathrm{f}, \mathrm{m}) \Rightarrow \mathrm{T}_{\mathrm{r}} \subseteq \mathrm{T}_{\mathrm{f}, \mathrm{m}} \Rightarrow \mathrm{T}_{\mathrm{rx}}=\left(\mathrm{T}_{\mathrm{r}}\right)_{\mathrm{x}} \subseteq\left(\mathrm{T}_{\mathrm{f}, \mathrm{m}}\right)_{\mathrm{x}}=\mathrm{T}_{\mathrm{f}_{\mathrm{x}, \mathrm{m}}}, \forall \mathrm{x} \in \mathrm{id}$

So we have $\mathrm{T}_{\mathrm{rx}} \subseteq \mathrm{T}_{\mathrm{fx}, \mathrm{m}}, \forall \mathrm{x} \in \mathrm{id} \Rightarrow \mathrm{r}_{\mathrm{x}}\left(\mathrm{f}_{\mathrm{x}}, \mathrm{m}\right), \forall \mathrm{x} \in \mathrm{id}$

ii) Under the assumption $\mathrm{r}(\mathrm{F}, \mathrm{m}) \Rightarrow \mathrm{T}_{\mathrm{r}} \subseteq \mathrm{T}_{\mathrm{F}, \mathrm{m}} \Rightarrow \mathrm{T}_{\mathrm{rx}}=\left(\mathrm{T}_{\mathrm{r}}\right)_{\mathrm{x}} \subseteq\left(\mathrm{T}_{\mathrm{F}, \mathrm{m}}\right)_{\mathrm{x}}=\mathrm{T}_{\mathrm{Fx}, \mathrm{m}}, \forall \mathrm{x} \in \mathrm{id}$

Therefore: $\mathrm{T}_{\mathrm{rx}} \subseteq \mathrm{T}_{\mathrm{Fx}, \mathrm{m}}, \forall \mathrm{x} \in \mathrm{id} \Rightarrow \mathrm{r}_{\mathrm{x}}\left(\mathrm{F}_{\mathrm{x}}, \mathrm{m}\right), \forall \mathrm{x} \in \mathrm{id}$

\section{Proposition 3.2}

Let $R=\left(i d ; A_{1}, A_{2}, \ldots, A_{n}\right), r(R)$ is a block on $R, U=\bigcup_{i=1}^{n} i d^{(i)}, f=\bigcup_{x \in i d} f_{x}$. Then:

i) If $r_{x}\left(f_{x}, m\right), \forall x \in i d$ then $r$ is $m$-satisfying the multivalued positive Boolean dependency $f: r(f, m)$.

ii) If $r_{x}\left(F_{x}, m\right), \forall x \in$ id then $r m$-satisfying set of multivalued positive Boolean dependency $F: r(F, m)$.

Proof

i) Under the assumption we have: $\mathrm{r}_{\mathrm{x}}\left(\mathrm{f}_{\mathrm{x}}, \mathrm{m}\right), \forall \mathrm{x} \in \mathrm{id} \Rightarrow \mathrm{T}_{\mathrm{rx}} \subseteq \mathrm{T}_{\mathrm{fx}, \mathrm{m}}, \forall \mathrm{x} \in \mathrm{id} \Rightarrow\left(\mathrm{T}_{\mathrm{r}}\right)_{\mathrm{x}} \subseteq\left(\mathrm{T}_{\mathrm{f}, \mathrm{m}}\right)_{\mathrm{x}}, \forall \mathrm{x} \in \mathrm{id}$

So we have: $\mathrm{T}_{\mathrm{r}} \subseteq \mathrm{T}_{\mathrm{f}, \mathrm{m}} \Rightarrow \mathrm{r}(\mathrm{f}, \mathrm{m})$.

$\Rightarrow r$ is $\mathrm{m}$-satisfying the multivalued positive Boolean dependency $\mathrm{f}$.

ii) Under the assumption $\mathrm{r}_{\mathrm{x}}\left(\mathrm{F}_{\mathrm{x}}, \mathrm{m}\right), \forall \mathrm{x} \in \mathrm{id} \Rightarrow \mathrm{T}_{\mathrm{rx}} \subseteq \mathrm{T}_{\mathrm{Fx}, \mathrm{m}}, \forall \mathrm{x} \in \mathrm{id} \Rightarrow\left(\mathrm{T}_{\mathrm{r}}\right)_{\mathrm{x}} \subseteq\left(\mathrm{T}_{\mathrm{F}, \mathrm{m}}\right)_{\mathrm{x}}, \forall \mathrm{x} \in \mathrm{id}$

So we have: $\mathrm{T}_{\mathrm{r}} \subseteq \mathrm{T}_{\mathrm{F}, \mathrm{m}} \Rightarrow \mathrm{r}(\mathrm{F}, \mathrm{m})$.

$\Rightarrow r$ m-satisfying set of multivalued positive Boolean dependency $\mathrm{F}$.

From the proposition 3.1 and 3.2 we have the following necessary and sufficient conditions:

\section{Theorem 3.2}

Let $R=\left(i d ; A_{1}, A_{2}, \ldots, A_{n}\right), r(R)$ is a block on $R, U=\bigcup_{i=1}^{n} i d^{(i)}, f=\bigcup_{x \in i d} f_{x}$. Khi dó:

i) $r_{x}\left(f_{x}, m\right), \forall x \in i d \Leftrightarrow r$ is $m$-satisfying the multivalued positive Boolean dependency $f: r(f, m)$.

ii) $r_{x}\left(F_{x}, m\right), \forall x \in i d \Leftrightarrow r m$-satisfying set of multivalued positive Boolean dependency $F$ : $r(F, m)$.

For the set PTBDĐT $F$ and PTBDĐT $f:, m \in[0 ; 1]$ : 
- We say $\mathrm{F}$ m-deduced $\mathrm{f}$ by the block and denoted $\left.\mathrm{F}\right|_{-\mathrm{m}} \mathrm{f}$ if: $\forall \mathrm{r}: \mathrm{r}(\mathrm{F}, \mathrm{m}) \Rightarrow \mathrm{r}(\mathrm{f}, \mathrm{m})$.

- We say $F \mathrm{~m}$-deduced $\mathrm{f}$ by the block contains no more than 2 elements and denoted $\left.\mathrm{F}\right|_{-2, \mathrm{~m}} \mathrm{f}$ if: $\forall \mathrm{r}_{2}: \mathrm{r}_{2}(\mathrm{~F}, \mathrm{~m}) \Rightarrow \mathrm{r}_{2}(\mathrm{f}, \mathrm{m})$.

We have the following equivalent theorem:

\section{Theorem 3.3}

For the set PTBDÐT F and PTBDÐT $f, R=\left(i d ; A_{1}, A_{2}, \ldots, A_{n}\right), r(R)$ is $\alpha$ block on $R, m \in B$. Then the following three propositions are equivalent:

(i) $\mathrm{F} \mid={ }_{m} \mathrm{f}$ (m-deduction by logic),

(ii) $\mathrm{F}{ }_{-m} \mathrm{f}$ (m-deduction by block),

(iii) $\mathrm{F} \mid-2, m \mathrm{f}$ (m-deduction by block has no more than 2 elements).

Proof

(i) => (ii): Under the assumption we have $F \mid={ }_{m} f \Rightarrow T_{F, m} \subseteq T_{f, m}^{(1)}$. Let $\mathrm{r}$ be an arbitrary block and $\mathrm{r}(\mathrm{F}, \mathrm{m})$, then by definition: $T_{r} \subseteq T_{F, m}^{(2)}$. From (1) and (2) we infer: $T_{r} \subseteq T_{f, m}$, so we have: $\mathrm{r}(\mathrm{f}, \mathrm{m})$.

(ii) $=>$ (iii): Obviously, because inference by the block has no more than 2 elements is the special case of inference by block.

(iii) $=>$ (i): Suppose $\mathrm{t}=\left(\mathrm{t}_{\mathrm{x}}^{(1)}, \mathrm{t}_{\mathrm{x}}^{(2)}, \ldots, \mathrm{t}_{\mathrm{x}}^{(\mathrm{n})}\right) \mathrm{x} \in \mathrm{id}, \mathrm{t} \in \mathrm{T}_{\mathrm{F}, \mathrm{m}}$ we need proof $: t \in T_{f, m}$.

Indeed, if $\mathrm{t}=\mathrm{e}$ then we have $t \in T_{f, m}$ because as we know $\mathrm{f}$ is a positive Boolean formula. If $t \neq e$, we built the block $\mathrm{r}$ including 2 elements $\mathrm{u}$ and $\mathrm{v}$ as follows: $\mathrm{u}=\left(\mathrm{u}_{\mathrm{x}}^{(1)}, \mathrm{u}_{\mathrm{x}}^{(2)}, \ldots, \mathrm{u}_{\mathrm{x}}^{(\mathrm{n})}\right)_{\mathrm{x} \in \mathrm{id}}, \mathrm{V}=\left(\mathrm{V}_{\mathrm{x}}^{(1)}, \mathrm{V}_{\mathrm{x}}^{(2)}, \ldots, \mathrm{V}_{\mathrm{x}}^{(\mathrm{n})}\right)_{\mathrm{x} \in \mathrm{id}}$ satisfy $\alpha(\mathrm{u}, \mathrm{v})=\mathrm{t}\left(\mathrm{mean}_{\mathrm{i}}\left(\mathrm{u}_{\mathrm{x}}^{(\mathrm{i})}, \mathrm{v}_{\mathrm{x}}^{(\mathrm{i})}\right)=\mathrm{t}_{\mathrm{x}}^{(\mathrm{i})}, 1 \leq \mathrm{i}\right.$ The existence of the $\mathrm{u}$ and $\mathrm{v}$ elements as above is due to the properties of the mappings $\alpha_{i}$ mentioned above. Thus $\mathrm{r}$ is a block with 2 elements and $\mathrm{T}_{\mathrm{r}}=\{\mathrm{e}, \mathrm{t}\} \subseteq \mathrm{T}_{\mathrm{F}, \mathrm{m}}$, with e is a element of block whose all component values are equal to 1 .

Thence inferred $r(F, m)$. Under the assumption we have $r(F, m)=>r(f, m)$, so that $T_{r} \subseteq T_{f, m}{ }^{(1)}$.

From (1) we infer $\mathrm{t} \in \mathrm{T}_{\mathrm{f}, \mathrm{m}}$.

\section{Consequence 3.2}

For the set PTBDĐT $F$ and PTBDĐT $f, R=\left(i d ; A_{1}, A_{2}, \ldots, A_{n}\right), r(R)$ is a block on $R, m \in B$. Then on $r_{x}$ the following three propositions are equivalent:

(i) $F_{x} \mid={ }_{m} f_{x}$ (m-deduction by logic),

(ii) $\left.F_{x}\right|_{-m} f_{x}$ (m-deduction by slice $\left.r_{x}\right)$,

(iii) $F_{x} \mid-2, m$ ( $f_{x}$ (m-deduction by the slice $r_{2 x}$ has no more than 2 elements).

In the case $\mathrm{id}=\{\mathrm{x}\}$, then the block degenerated into a relation and the above m-equivalence theorem becomes the $\mathrm{m}$ equivalent theorem in the relational data model. Specifically, we have the following consequences:

\section{Consequence 3.3}

For the set PTBDĐT $F$ and PTBDĐT $f, R=\left(i d ; A_{1}, A_{2}, \ldots, A_{n}\right), r(R)$ is a block on $R, m \in B$. Then if id $=\{x\}$ then block $r$ degenerates into relation and the following three propositions are equivalent:

(i) $F \mid={ }_{m} f(m$-deduction by logic $)$,

(ii) $F \mid-m f(m$-deduction by relation),

(iii) $\left.F\right|_{-2, m} f$ ( $m$-deduction by relation has no more than 2 elements).

\section{Definition 3.7}

Let $R=\left(i d ; A_{1}, A_{2}, \ldots, A_{n}\right), r(R)$ is a block on $R, U=\bigcup_{i=1}^{n} i d^{(i)}, m \in B$. $\sum$ is a subset of PTBDĐT on $U$, we denoted $\left(\sum, m\right)^{+}$is the set of all PTBDĐT are $m$-deduction from $\sum$, in other words:

$$
(\Sigma, m)^{+}=\left\{g \in M V P(U)|\Sigma|=_{m} g\right\}=\left\{g \in M V P(U) \mid T_{\Sigma, m} \subseteq T_{g, m}\right\}
$$

\section{Definition 3.8}

Let $R=\left(i d ; A_{1}, A_{2}, \ldots, A_{n}\right), r(R)$ is a block on $R, U=\bigcup_{i=1}^{n} i d^{(i)}, m \in B$, we denoted MBDĐT( $\left.r, m\right)$ is the set of all PTBDĐT $m$-right in $r$, In other words:

$$
\operatorname{MBDĐT}(\mathrm{r}, \mathrm{m})=\{\mathrm{g} \in \operatorname{MVP}(\mathrm{U}) \mid \mathrm{r}(\mathrm{g}, \mathrm{m})\}
$$

So, we have:

$$
g \in \mathrm{MBD} T(\mathrm{r}, \mathrm{m}) \Leftrightarrow g \in \mathrm{MVP}(\mathrm{U}) \wedge \mathrm{T}_{\mathrm{r}} \subseteq \mathrm{T}_{\mathrm{g}, \mathrm{m}}
$$




\section{Theorem 3.4}

Let $R=\left(i d ; A_{1}, A_{2}, \ldots, A_{n}\right), r(R)$ is a block on $R, U=\bigcup_{i=1}^{n} i^{(i)}, m \in \mathrm{B}$. Then we have:

$$
(M B D Đ T(r, m), m)^{+}=\operatorname{MBDĐT}(r, m)
$$

Proof

By definition, we have:

$$
(\operatorname{MBDĐT}(r, m), m)^{+}=\{g \in M V P(U)|\operatorname{MBDĐT}(r, m)|=m g\}
$$

Apply the result of the theorem of three equivalent propositions for PTBDĐT, we have:

$$
\left\{\mathrm{g} \in \operatorname{MVP}(\mathrm{U})|\operatorname{MBD} T(r, m)|={ }_{m} g\right\}=\left\{\mathrm{g} \in \operatorname{MVP}(\mathrm{U})|\operatorname{MBD} T(r, m)|_{-m} g\right\}
$$

From $(1)$ and $(2)$ we infer: $(\operatorname{MBDĐT}(r, m), m)^{+}=\operatorname{MBDĐT}(r, m)$.

So two sets $(\mathrm{MBD} Ð \mathrm{~T}(\mathrm{r}, \mathrm{m}), \mathrm{m})^{+}$and $\mathrm{MBDÐT}(\mathrm{r}, \mathrm{m})$ are two sets PTBDĐT m-equivalents on blocks.

\section{Consequence 3.4}

Let $R=\left(i d ; A_{1}, A_{2}, \ldots, A_{n}\right), r(R)$ is a block on $R, U=\bigcup_{i=1}^{n} i d^{(i)}, m \in \mathrm{B}$. Then on $r_{x}$ we have:

$$
\left(\operatorname{MBDĐT}\left(r_{x}, m\right), m\right)^{+}=\operatorname{MBDĐT}\left(r_{x}, m\right), x \in i d
$$

\section{Consequence 3.5}

Let $R=\left(i d ; A_{1}, A_{2}, \ldots, A_{n}\right), r(R)$ is a block on $R, m \in B$. Then we have, if id $=\{x\}$ then block $r$ degenerates into relation and we have in the relational data model:

$$
(M B D Đ T(r, m), m)^{+}=M B D Đ T(r, m)
$$

\section{Definition 3.9}

Let $R=\left(i d ; A_{1}, A_{2}, \ldots, A_{n}\right), r(R)$ is a block on $R, U=\bigcup_{i=1}^{n} i^{(i)}, m \in \mathrm{B}, \Sigma$ is the subset of PTBDĐT on $U$. We say block $r$ is $m$ representation set $\Sigma$ if $\operatorname{MBD} Đ T(r, m) \supseteq(\Sigma, m)^{+}$and we say block $r$ is $m$-tight representation set $\Sigma$ if $\operatorname{MBD} Đ T(r, m)=(\Sigma, m)^{+}$

If $\mathrm{r}$ is $\mathrm{m}$-tight representation set PTBDĐT $\Sigma$ then we say $\mathrm{r}$ is the block $\mathrm{m}$-Armstrong of set PTBDĐT $\Sigma$.

\section{Theorem 3.5}

Let $R=\left(i d ; A_{1}, A_{2}, \ldots, A_{n}\right), m \in B$. Then, with every block $r(R)$ different from the empty set on $R$ we have:

$$
\mathrm{T}_{\mathrm{r}}=\mathrm{T}_{\mathrm{MBD}} T(\mathrm{r}, \mathrm{m}), \mathrm{m}
$$

Proof

Suppose $\mathrm{g} \in \operatorname{MBDĐ} T(\mathrm{r}, \mathrm{m}) \Rightarrow \mathrm{r}$ is m-satisfying $g \Leftrightarrow T_{r} \subseteq T_{g, m}$. From $\mathrm{T}_{r}$ and value $\mathrm{m}$, According to theorem 3.1 we find a multivalued boolean formula $\mathrm{f}$ satisfying conditions: $\mathrm{f}(\mathrm{e})=1$ và $\mathrm{T}_{f, m}=\mathrm{T}_{r}$. So: $\mathrm{e} \in \mathrm{T}_{\mathrm{r}}=\mathrm{T}_{\mathrm{f}, \mathrm{m}}$ infer $\mathrm{f}$ is one CTBDĐT and and more due $T_{r}=T_{f, m} \Rightarrow r$ is m-satisfying $f$, mean: $f \in \operatorname{MBDĐT~}(\mathrm{r}, \mathrm{m})$.

We denoted: $F=\operatorname{MBDĐT}(r, m)$, from the above proof we have:

$$
\begin{gathered}
\forall \mathrm{g} \in \operatorname{MBD} T(\mathrm{r}, \mathrm{m}) \Rightarrow \mathrm{T}_{\mathrm{r}} \subseteq \mathrm{T}_{\mathrm{g}, \mathrm{m}} \Rightarrow \mathrm{T}_{\mathrm{r}} \subseteq \bigcap_{g \in F} T_{g, m} \\
\quad \exists \mathrm{f} \in \operatorname{MBD} T(\mathrm{r}, \mathrm{m}): \mathrm{T}_{\mathrm{r}}=\mathrm{T}_{\mathrm{f}, \mathrm{m}} \Rightarrow \mathrm{T}_{\mathrm{r}} \supseteq \bigcap_{g \in F} T_{g, m}
\end{gathered}
$$

From (3) and (4) we infer:

$$
\mathrm{T}_{\mathrm{f}}=\bigcap_{g \in F} T_{g, \bar{m}}=\mathrm{T}_{\mathrm{F}, \mathrm{m}}
$$

Thus: $\mathrm{T}_{\mathrm{t}}=\mathrm{T}_{\mathrm{MBD} T(\mathrm{r}, \mathrm{m}), \mathrm{m}}$. 


\section{Consequence 3.6}

Let $R=\left(i d ; A_{1}, A_{2}, \ldots, A_{n}\right), r(R)$ is a block on $R, m \in B$. Then, on the slice $r_{x}$ we have:

$$
\mathrm{T}_{\mathrm{Tx}}=\mathrm{T}_{\mathrm{MBD} T(\mathrm{r}, \mathrm{m}), \mathrm{m}}, x \in i d
$$

\section{Consequence 3.7}

Let $R=\left(\right.$ id; $\left.A_{1}, A_{2}, \ldots, A_{n}\right), r(R)$ is a block on $R, \mathrm{~m} \in B$. Then we have, if id $=\{x\}$ then block $r$ degenerates into relation and we have in the relational data model: $T_{r}=T_{M B D \oplus T(r, m), m}$.

\section{Theorem 3.6}

Let $R=\left(i d ; A_{1}, A_{2}, \ldots, A_{n}\right), U=\bigcup_{i=1}^{n} i d^{(i)}, m \in \mathrm{B}, \Sigma$ is the subset of PTBDÐT on $U$. Then, with every block $r(R)$ is otherwise empty on $R$ we have: $r$ is m-tight representation set PTBDÐT $\sum$ if and only if $\mathrm{T}_{\mathrm{r}}=\mathrm{T}_{\Sigma, \mathrm{m}}$.

Proof

By definition, we have: $\mathrm{r}$ is $\mathrm{m}$-tight representation set $\Sigma \Leftrightarrow \operatorname{MBDĐ} T(\mathrm{r}, \mathrm{m})=(\Sigma, \mathrm{m})^{+} \Leftrightarrow \quad \operatorname{MBDĐ} T(\mathrm{r}, \mathrm{m}) \equiv_{\mathrm{m}} \sum$.

Other way:

$$
\operatorname{MBDĐ} T(\mathrm{r}, \mathrm{m}) \equiv_{\mathrm{m}} \Sigma \Leftrightarrow \mathrm{T}_{\mathrm{MBD} T(\mathrm{r}, \mathrm{m}), \mathrm{m}}=\mathrm{T}_{\Sigma, \mathrm{m}}
$$

Apply the results of theorem 3.4 we obtain:

$$
\mathrm{T}_{\mathrm{r}}=\mathrm{T}_{\mathrm{MBD}} T(\mathrm{r}, \mathrm{m}), \mathrm{m}
$$

So from (5) and (6) we infer: $\mathrm{T}_{r}=\mathrm{T}_{S, m}$.

Therefore: $\mathrm{r}$ is $\mathrm{m}$-tight representation set $\Sigma \Leftrightarrow \mathrm{T}_{x}=\mathrm{T}_{\Sigma, \mathrm{m}}$.

\section{Consequence 3.8}

Let $\mathrm{R}=\left(\mathrm{id} ; \mathrm{A}_{1}, \mathrm{~A}_{2}, \ldots, \mathrm{A}_{n}\right), U=\bigcup_{i=1}^{n}$ id ${ }^{(i)}, m \in \mathrm{B}$, Eis the subset of PTBDÐT on $U$. Then we have, if $i d=\{x\}$ then block $r$ degenerated into relation and we have in the relational data model: every relation $r$ is different from the empty set on $R$ is $m$-tight representation set PTBDĐT $\Sigma$ if and only if $T_{r}=T_{\sum, m}$.

This consequence is exactly what we already know in the relational data model.

We denoted $\Sigma_{\mathrm{x}}=\Sigma \cap \bigcup_{i=1}^{n} x^{(i)}$

\section{Theorem 3.7}

Let $\mathrm{R}=$ (id; $\mathrm{A}, \mathrm{A}, \ldots, \mathrm{A}), U=\bigcup_{i=1}^{n} i d^{(i)}, m \in \mathrm{B}$, Lis the subset of PTBDÐT on if $U, \Sigma=\bigcup_{x \in i d} \Sigma_{x}, \quad \Sigma_{x} \neq \varnothing$ Then, with every block $r(R)$ is otherwise empty on $R$ we have: $r$ is $m$-tight representation set PTBDĐT $\Sigma$ if and only if $r_{x}$ is $m$-tight representation set $\Sigma_{x}, \forall x \in i d$.

Proof

$\Rightarrow$ ) Suppose $\mathrm{r}$ is m-tight representation set PTBDĐT $\Sigma$ we need proof $\mathrm{r}_{x}$ is $\mathrm{m}$-tight representation set $\Sigma_{\mathrm{x}}, \forall \mathrm{x} \in \mathrm{id}$.

Indeed, under the assumption we have: $r$ is $\mathrm{m}$-tight representation set PТВDÐТ $\Sigma$, using the results of theorem 3.6 we have: $\mathrm{T}_{\mathrm{r}}=\mathrm{T}_{\Sigma, \mathrm{m}}$.

Thence inferred: $\left(\mathrm{T}_{\mathrm{r}}\right)_{\mathrm{x}}=\left(\mathrm{T}_{\Sigma, \mathrm{m}}\right)_{\mathrm{x}}, \forall \mathrm{x} \in$ id.

Which we have: $\mathrm{T}_{\mathrm{rx}}=\left(\mathrm{T}_{\mathrm{r}}\right)_{\mathrm{x}}=\left(\mathrm{T}_{\Sigma, \mathrm{m}}\right)_{\mathrm{x}}=\mathrm{T}_{\Sigma \mathrm{x}, \mathrm{m}}, \forall \mathrm{x} \in \mathrm{id} \Rightarrow \mathrm{T}_{\mathrm{rx}}=\mathrm{T}_{\Sigma \mathrm{x}, \mathrm{m}} \Rightarrow \mathrm{r}_{\mathrm{x}}\left(\Sigma_{\mathrm{x}}, \mathrm{m}\right), \forall \mathrm{x} \in$ id.

So $\mathrm{r}_{x}$ is $\mathrm{m}$-tight representation $\operatorname{set} \Sigma_{\mathrm{x}}, \forall \mathrm{x} \in \mathrm{id}$.

$\Leftrightarrow)$ Suppose $\mathrm{r}_{x}$ is $\mathrm{m}$-tight representation set $\Sigma_{\mathrm{x}}, \forall \mathrm{x} \in$ id we need proof $\mathrm{r}$ is $\mathrm{m}$-tight representation set $\Sigma$.

Indeed, under the assumption $\mathrm{r}_{x}$ is m-tight representation set $\Sigma_{\mathrm{x}}, \forall \mathrm{x} \in \mathrm{id} \Rightarrow \mathrm{T}_{\mathrm{rx}}=\mathrm{T}_{\Sigma x, \mathrm{~m}}, \forall \mathrm{x} \in \mathrm{id}$.

Inferred: $\left(\mathrm{T}_{\mathrm{r}}\right)_{\mathrm{x}}=\mathrm{T}_{\mathrm{rx}}=\mathrm{T}_{\Sigma \mathrm{x}, \mathrm{m}}=\left(\mathrm{T}_{\Sigma, \mathrm{m}}\right)_{\mathrm{x}}, \quad \forall \mathrm{x} \in \mathrm{id}$

Which we have: $\mathrm{T}_{\mathrm{r}}=\bigcup_{x \in \text { id }} T_{r x}, \mathrm{~T}_{\Sigma, \mathrm{m}}=\bigcup_{\mathrm{x} \in \mathrm{id}} T_{\Sigma x, \mathrm{~m}} \Rightarrow \mathrm{T}_{\mathrm{r}}=\mathrm{T}_{\Sigma, \mathrm{m}}$.

So $r$ is $\mathrm{m}$-tight representation set PTBDĐT $\Sigma$.

\section{Conclusions}

From the proposed new concept: multivalued positive Boolean dependence on block and slice, the article defined the truth block of the data block, prove the completeness of the set of functions $\{I, \wedge, \vee\}$. In addition, the article also proves the equivalent theorem for multivalued positive Boolean dependencies on block and slice. The necessary and sufficient condition for a block 
is $\mathrm{m}$-tight representation $\sum \ldots$ If $\mathrm{id}=\{\mathrm{x}\}$ then the block degenerated into a relation and the results found on the block are still true on the relation.

We can further study the relationship between other types of logical dependencies on block and slice, extend the set of function dependencies on the block,... contribute to further complete design theory of the database model of block form.

\section{Acknowledgements}

The authors thank the teachers, leaders of the Institute of Information Technology and the Management Board of the Hanoi Pedagogical University 2 for creating favorable conditions for us to work and study. This research is funded by Hanoi Pedagogical University 2 (HPU2).

\section{References}

1) Huy TDNX and Thang. The database model of blocks form. Journal of Informatics and Cybernetics. 1998;T. 14(S.3):52-60.

2) Thang TD and Tuyen TM. The translation of block scheme and the present problem of the closure, key in the database model of block forms. In: and others, editor. Proceedings of the National Conference XIII "Some the selected issues of Information Technology and Communication" . 2010,. p. 276-286.

3) Thang TD and Tuyen TM. Closed mapping and translation of block schemes. In: and others, editor. Proceedings of the National Conference on the VI for Fundamental and Applied Information Technology Research (FAIR) . 2013,. p. 677-683.

4) Thang TD, Tuyen TM and Truc TN. Deductive formula in the database model of block forms. In: and others, editor. Proceedings of the National Conference on the VIII for Fundamental and Applied Information Technology Research (FAIR) . 2015,. p. 103-110. Available from: https://doi.org/10.15625/vap.2015. 000143.

5) Huy NX. Logical dependencies in the database. HaNoi. Statistical Publisher . 2006, 